\title{
Investigation of the Effect of Acute Muscular Fatigue on Static and Dynamic Balance Performances in Elite Wrestlers
}

\author{
Ömer Özer ${ }^{1}$ \\ ${ }^{1}$ Physical Education and Sport, Karamanoğlu Mehmetbey University, Karaman, Turkey \\ Correspondence: Ömer Özer, Physical Education and Sport, Karamanoğlu Mehmetbey University, Physical \\ Education and Sport, Karaman, Turkey. E-mail: besyo4307@gmail.com
}

Received: August 8, 2019

Accepted: August 30, 2019 Online Published: September 20, 2019

doi:10.5539/jel.v8n5p179

URL: https://doi.org/10.5539/jel.v8n5p179

\begin{abstract}
Maximal strength, muscular endurance, maximal aerobic power, and anaerobic capabilities, power are needed to have victory for wrestlers in a wrestling competition. The aim of the study is to investigate the effect of acute muscular fatigue on static and dynamic balance performances in elite wrestlers. Ten elite male wrestlers $(25 \pm 2.3$ years, $181 \pm 6.5 \mathrm{~cm}, 84 \pm 4.2 \mathrm{~kg}$ ) participated in the study voluntarily. Participants were undertaken dynamic and static balance test before fatigue exercise (in Cybex) and immediately after fatigue exercise, theywere undertaken dynamic and static balance test again. SPSS packet program was used to evaluate the data. There were no statistically significant differences in static and dynamic balance before and after fatigue. The results show that wrestlers' balance is not affected by muscular fatigue, so there is no need for balance exercise after fatigue at least according to this study.
\end{abstract}

Keywords: wrestlers, balance, strength

\section{Introduction}

Wrestling is one of the oldest martial arts practices dating back to $708 \mathrm{BC}$ at the ancient Greek Olympic Games (Barroso et al., 2011). It is known that there are 2 internationally recognized forms of competitive wrestling. One of the is Freestyle and the other is Greco-Roman. In Greco-Roman competition, wrestlers just can use their upper body and just attack to rival's upper body but in Freestyle competition, wrestlers can use their entire body and they can attack to rival's entire body. The main goal of the wrestlers is to be physically superior to the other. Wrestlers have to be adopted to repetitive bouts of high-intensity actions to be successful. Maximal strength, muscular endurance, maximal aerobic power, and anaerobic capabilities, power are needed to have victory for wrestlers in wrestling competition (Chaabene et al., 2017).

The human body has to be in great balance physical, physiological, biomotoric (Çakmakçi et al., 2018; Tatlici et al., 2018), if they have a higher level of technical and higher fitness components, wrestlers can show higher performance. Anaerobic power and capacity are crucial variables for having a high level of performance and one of the main parameters that distinguish successful and less successful wrestlers regardless of age categories, weight classes, and wrestling styles. Anaerobic parameters are so important for wrestling because during a wrestling match, high repetitive bouts of high-intensity actions are needed and these actions energy is come from anaerobic energy systems. Another parametre of being a high level of wrestlers is muscle power. Wrestling competition is related by rapid explosive moves and rival's attacks for lifting rival powerfully, so that bring $\mathrm{him} / \mathrm{her}$ to the mat and to have an advantage. Strength-endurance level is needed in a wrestling match because of wrestling moves load, length of time of movements, and intensity of movements (Sterkowicz et al., 2005). A wrestling match consists of a series of dynamic movements of the legs, hips, and back and also involves isometric grasping for position maintenance. It has been shown that these patterns of muscular force appear sensitive to the accumulated effects of fatigue i.e., muscle damage or acid-base balance (McGuigan et al., 2006).

As the other martial arts, wrestling needs strength and balance. Also, wrestlers have to increase their strength parameters to avoid injuries risk (Hosseınımehret et al., 2009; Muehlbauer et al., 2013; Ringsberget et al., 1999). Balance can be considered as an improved movement technique and condition element. Balance divided into two components; dynamic and static. Dynamic balance includes postural control, neuromuscular control, power, flexibility and coordination components of the lower extremity and tries to maintain the body position in motion. Static balance; postural control, lower extremity cutaneous, articulation and muscular information, including the 
visual return and aiming to keep the body steady when inactive. It is possible to prevent loss of energy transfer from lower extremity to the upper extremity in stable platforms where balance is achieved and it can provide better performance. Muscular fatigue (MF) is defined as any declining in the neuromuscular ability for producing strength (Gribble et al., 2004).

The onset of volunteer muscle activity involves several procedures that begin with cortical control in the brain and end with bridges within the muscle fiber. Consequently, muscle fatigue can be in consequence of a failure in any process involved in muscle contraction (Johnstonet et al., 1998). Until recently, proprioception and balance were examined but currently, fatigue and postural control relation have been examining intensely by researchers. Most of the studies about fatiguing evaluated with static postural control (Gierczuket et al., 2008; Nakagawa et al., 2004). Therefore, our study is to investigate the effects of muscular fatigue (Isokineticstrength exercise) on dynamic and static balance in elite wrestlers.

\section{Method}

\subsection{Sample and Procedure}

Ten Greco-Roman wrestlers participated in the study. Wrestlers played in national and international tournament repeatedly. Participants were informed about the aim and the risks of the study. All participants provided with written informed consent.

Table 1. Descriptive characteristics of the sample

\begin{tabular}{lll}
\hline & $\mathrm{N}$ & Mean \\
\hline Age $(\mathrm{y})$ & 10 & $25 \pm 2.3$ \\
Body height $(\mathrm{cm})$ & 10 & $181 \pm 6.5$ \\
Body mass $(\mathrm{kg})$ & 10 & $84 \pm 4.2$ \\
\hline
\end{tabular}

Participants were taken to the sports science faculty laboratory at $10.00 \mathrm{am}$. Participants were warned to not participate in any exercise in the past 48 hours until the end of the test section. Participants were informed about the amount and type of food (55\% carbohydrates, $25 \%$ lipids and $20 \%$ protein due to energy metabolism) that they had to take 24 hours prior to trial day (Tatlıcı \& Çakmakçı, 2019). Subjects were applied to standard warm-up including stretching movements. Following that, participants' dynamic balances and static balance were taken by Biodex Balance System (BBS, Biodex Medical Systems Inc., Shirley, NY). The participants who completed the balance test were then immediately taken to the isokinetic knee strength test.1-minute rest was given between the velocities and 5-minutes were given between knee changes (Rahnamaet al., 2005).

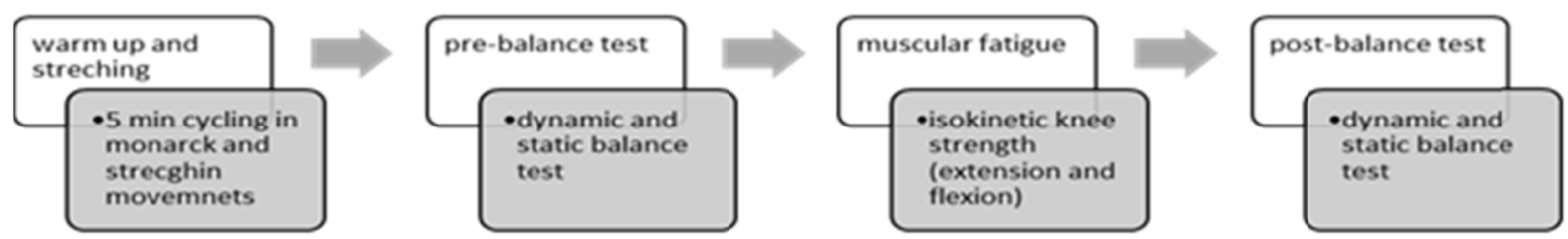

Figure 1. Time template of study

\subsection{Data Collection Tool}

\subsubsection{Dynamic and Static Balance Testing}

The participant's dynamic balance (open eyes) and static balance were measured. Two tests were performed to each participant for the familiarization purposes before the measurement, and then two more measurements were made for both the dominant and the non-dominant leg. Subjects were subjected to balance test on one foot by holding their hands on the shoulders of the crossed position after standing on the BBS's mobile platform. The level of difficulty of the measuring instrument was set to "Level 4" for the dynamic balance condition. In the static balance condition, the ground was static. Other leg did not touch the ground and participant were not allowed to look at the BSS monitor. 3 separate balance scores were obtained after the automatically completed test [Overall 
Stability Index (OSI), Anterior-Posterior Index (APSI), Medio-Lateral Index (MLSI)].

\subsubsection{Isokinetic Strength Exercise}

The isokinetic knee strength exercise was performed with an isokinetic dynamometer (Cybex, Humac Norm, 2004) in the kinanthropometry laboratory of Selcuk University. Wrestlers participating in the study were taken to the isokinetic knee exercise after warming up. Participants are seated in the correct position in the test seat. The participants' holders and the middle sections of the thighs were stabilized to the seat by the tapes. In addition, they were allowed to support by holding the handles on the right and left sides of the seat during the exercise.

Five repeats maximal contractions knee extension (hamstring) and flexion (quadriceps) torque values were obtained at $60^{\circ}$ sec- 1 speed. In addition, 15 repeats maximal contractions exercise were done at $180^{\circ}$ sec- 1 speed. Peak power and average power of both legs were recorded during exercise for seeing how they spend effort. Participants were supported by verbally with encouraging expressions in order to achieve higher performance during the exercise. Also, the best values were recorded during the exercise.

\subsection{Data Analyses}

All statistical tests were performed using the software package SPSS version 22.0 (SPSS Inc, Chicago, IL). Paired sample T-test was done for comparing the Pre and Post balance tests. Data are provided as the mean (M) and standard deviation (SD). The statistical significance level was set at $\mathrm{p}<0.05$.

\section{Results}

Table 2. Descriptive characteristics of the sample

\begin{tabular}{|c|c|c|}
\hline Parametres (Newton meter) & Mean & Std. Deviation \\
\hline Extension $60^{\circ \text { sec-1 }}$ peakpower & 241.50 & 49.79 \\
\hline flexion_6 $60^{\circ \text { sec-1 }}$ _peakpower & 140.00 & 29.03 \\
\hline extension_ $60^{\circ} \stackrel{\overline{\text { sec }}}{-}$ avaregepower & 163.40 & 27.39 \\
\hline flexion_60 $60^{\circ \text { sec-1 }}$ avaragepower & 100.80 & 19.53 \\
\hline extension_ $180^{\circ \text { sec-1 }}$ peakpower & 164.00 & 29.40 \\
\hline flexion_180 ${ }^{\circ}$ sec- 1 _peakpower & 87.30 & 15.98 \\
\hline extension_ $180^{\circ \text { sec-1 }} \_^{-T o t a l}$ work done & 1978.70 & 354.25 \\
\hline flexion_ $180^{\circ \text { sec-1 }}$ _ Total work done & 936.70 & 151.15 \\
\hline
\end{tabular}

Table 3. Comparison of static balance tests (pre and post)

\begin{tabular}{llllll}
\hline Parametres & Mean & Std. Deviation & Minimum & Maximum & P \\
\hline Pre-OSI & 2.32 & .35 & 1.80 & 2.90 & .126 \\
Post-OSI & 2.66 & .65 & 1.70 & 4.10 & \\
Pre-APSI & 1.75 & .36 & 1.40 & 2.60 & .275 \\
Post-APSI & 1.92 & .53 & 1.20 & 2.90 & \\
Pre- MLSI & 1.26 & .27 & .70 & 1.50 & .539 \\
Post-MLSI & 1.38 & .60 & .90 & 2.90 & \\
\hline
\end{tabular}

Note. OSI= Overall Stability Index; APSI= Anterior-Posterior Stability Index; MLSI= medial-lateral stability Index.

When the pre and post balance test values are evaluated, there were no significant differences between pre and post static balance tests of participants.

Table 4. Comparison of dynamic balance tests (pre and post)

\begin{tabular}{llllll}
\hline Parametres & Mean & Std. Deviation & Minimum & Maximum & P \\
\hline Pre-OSI & 2.16 & .54 & 1.40 & 3.10 & .649 \\
Post-OSI & 2.28 & .70 & 1.30 & 3.70 & \\
Pre-APSI & 1.47 & .44 & .90 & 2.20 & .255 \\
Post-APSI & 1.75 & .68 & .80 & 3.10 & \\
Pre-MLSI & 1.25 & .48 & .60 & 2.30 & .464 \\
Post-MLSI & 1.12 & .19 & .90 & 1.50 & \\
\hline
\end{tabular}

Note. OSI= Overall Stability Index; APSI= Anterior-Posterior Stability Index; MLSI= medial-lateral stability Index. 
It was found that there was no significant difference between the two parameters when the pre and post dynamic and static balance performances of the participants were compared.

\section{Discussion}

\subsection{Study Limitations and Implications for Future Assessment}

It was investigated in the study that the effect of acute muscular fatigue on static and dynamic balance performances in elite wrestlers. There were no significant differences between pre and post static balance tests of participants when the pre and post balance test values are evaluated. Also, there were no significant differences between pre and post static balance tests of participants. When the reviewing literature, there are few studies on the evaluation of balance parameters before and after acute fatigue in wrestlers. Letafatkar and Milaei (2012) evaluated the balance parameters before and after the wrestling competition in their study. They used a similar sample group and similar balance system. Wrestlers' balance did not change significantly after fatigue. Iri et al. (2016) conducted a study on 17 female wrestlers, metabolic fatigue wrestling before and after the balance measurements were made. They found a statistically significant difference in post static and dynamic balance parameters. The results of this study are in contradiction with the results of our study. These differences could be derived from the subject's gender. The central nervous system (CNS) and local fatigue factors can reduce body balance performance. Central (whole-body), fatigue refers to a decline in the CNS output to the muscles and possibly got a component that involved factors responsible for the sense of effort in addition to the changes in motor pathways. Local muscle fatigue results in a decrease in metabolic substrates present for muscle contraction, such as adenosine triphosphate, creatine phosphate, and glycogen, resulting in increased metabolites, including lactic acid in muscle, and discontinuation, therefore, a desired muscle strength output (Wilkins, 2004). Maybe this can be the reason that local muscle fatigue can not affect balance performance.

According to the studies done without creating fatigue, Gierczuk (2008) found no statistically significant difference in the dynamic balance of Greco-Roman wrestlers and static balance parameters of the free wrestlers after a specific training program, which they had complied for 6 hours a week on a total of 32 free and Greco-Roman wrestlers. In Arabac1 et al. (2019) study, 11 elite wrestlers' body composition on the static force, anaerobic power, and static balance show statistical differences. Başar et al. (2014) found no statistically significant difference between the parameters of force, flexibility and balanced on the 46 Greco-Roman and 35 freestyle wrestlers. Tatlici and Unlu (2018) investigated the effect of acute PNF stretching on balance in wrestlers but the result shows that PNF did not affect the balance of wrestlers. As well as Morán-Navarro et al. (2015), found that elite and non-elite wrestler's parameters of ankle injuries cause a statistically significant effect on the static and dynamic balance.

Although in the literature, there are limited studies about fatigue and balance in wrestlers, there are some studies on other branches. Soslu et al. (2018) used Wingate anaerobic power and capacity testing (Want) to establish the low extremity fatigue index of the elite 10 men boxers in order to investigate the effect of acute fatigue on the static balance of the boxers. They found significant differences after fatigue on balance of boxers. In the study of Çelenk (2018), the static and dynamic balance parameters of 29 teams and 26 individuals were compared and could not find a statistically significant difference.

\subsection{Conclusion}

In the present study, the balance performance of wrestlers did not change with high-intensity muscular effort. It can be said in the light of all information that, muscular fatigue is not able to affect the balance performance at least in terms of this study. it can be said that there are very few studies before and after the acute fatigue on the wrestlers in the literature and this study contributed greatly to the literature because of the acute fatigue in the laboratory environment compared to similar studies. In the future studies, a different variation of fatigue test can be used and the female wrestlers can include into studies. Also, hearing-impaired individuals can be investigated because of balance differences (Tatlici et al., 2018).

\section{References}

Arabac1, R., Topçu, H., \& Vardar, T. (2019). The relationship between some physical fitness characteristics and body composition of elite wrestlers. International Journal of Physical Education, Fitness and Sports, 8(1), 25-32. https://doi.org/10.26524/ijpefs1913

Barroso, B. G., da Silva, J. M. A., Garcia, A. D. C., Ramos, N. C. D. O., Martinelli, M. O., Resende, V. R., ... Santili, C. (2011). Musculoskeletal injuries in wrestling athletes. Acta Ortop Bras, 19, 98-101. https://doi.org/10.1590/S1413-78522011000200007

Basar, S., Duzgun, I., Guzel, N. A., Cicioğlu, I., \& Çelik, B. (2014). Differences in strength, flexibility and stability 
in freestyle and Greco-Roman wrestlers. Journal of Back and Musculoskeletal Rehabilitation, 27(3), 321330. https://doi.org/10.3233/BMR-130451

Chaabene, H., Negra, Y., Bouguezzi, R., Mkaouer, B., Franchini, E., Julio, U., \& Hachana, Y. (2017). Physical and physiological attributes of wrestlers: an update. The Journal of Strength \& Conditioning Research, 31(5), 1411-1442. https://doi.org/10.1519/JSC.0000000000001738

Çakmakçi, E., Tatlici, A., \& Yirmibeş, B. (2018). Comparison of Some Performance Parameters of Physically Active Mentally Retarded and Inactive Mentally Retarded Individuals. European Journal of Physical Education and Sport Science.

Çelenk, Ç., Arslan, H., Aktuğ, Z. B., \& Şimşek, E. (2018). The Comparison Between Static and Dynamic Balance Performances of Team and Individual Athletes. European Journal of Physical Education and Sport Science.

Garcia, P. J., Lopez-Gullon, J. M., Torres-Bonete, M. D., \& Izquierdo, M. (2012). Physical fitness factors to predict female Olympic wrestling performance and sex differences. Journal of Strength and Conditioning Research, 26, 794-803. https://doi.org/10.1519/JSC.0b013e31824741e7

Gierczuk, D. (2008). Level Of Selected Indicators Of Coordination Motor Abilities (Cma) In Greco-Roman And Freestyle Wrestlers Aged 13-14. Polish Journal of Sport \& Tourism, 15(4).

Gribble, P. A., \& Hertel, J. (2004). Effect of lower-extremity muscle fatigue on postural control. Journal of Archives of Physical Medicine and Rehabilitation, 85, 589-592. https://doi.org/10.1016/j.apmr.2003.06.031

Hosseınımehr, S. H., Norasteh, A. A., Daneshmand1, H., Rahpemay-Rad, K., \& Rahımı, R. (2009). The effect of vibration on leg muscles proprioception in static and dynamic postural control. Journal of Medicinadello Sport, 62, 35-43.

Iri, R., Aktug, Z. B., Koc, M., Sahin, I., \& Murathan, F. (2016). The effect of fatigue in elite young female wrestlers upon balance performance and reaction time. Biomedical Research, 27(4), 1166-1170.

İbiş, S. (2017). The relationship of balance performance in young female national team wrestlers with strength, leg volume and anthropometric features. Biomedical Research, 28(1), 92-97.

Johnston, R. B., Howard, M. E., Cawley, P. W., \& Lossee, G. M. (1998). Effect of lower extremity muscular fatigue on motor control performance. Medicine and Science in Sports and Exercise, 30, 1703-1707. https://doi.org/10.1097/00005768-199812000-00008

Letafatkar, A., \& Milaei, M. (2012). Being In Context And Similarity In Fatiguing Protocols To Main Aspects Of Wrestling Don't Alter The Balance. Sport Scientific \& Practical Aspects, 9(2). https://doi.org/10.1080/21615667.2012.10878947

McGuigan, M. R., Winchester, J. B., \& Erickson, T. (2006). The importance of isometric maximum strength in college wrestlers. Journal of Sports Science \& Medicine, 5(CSSI), 108.

Morán-Navarro, R., Valverde-Conesa, A., López-Gullón, J. M., la Cruz-Sánchez, D., \& Pallarés, J. G. (2015). Can balance skills predict Olympic wrestling performance? Journal of Sport \& Health Research, 7(1).

Muehlbauer, T., Gollhofer, A., \& Granacher, U. (2013), Association of balance, strength, and power measures in young adults. The Journal of Strength \& Conditioning Research, 27, 582-589. https://doi.org/10.1519/JSC.0b013e31825c2bab

Nakagawa, L., \& Hoffman, M. (2004). Performance in static, dynamic, and clinical tests ofpostural control in individuals with recurrent ankle sprains. Journal of Sport Rehabilitation, 13, 255-268. https://doi.org/10.1123/jsr.13.3.255

Rahnama, N., Lees, A., \& Bambaecichi, E. (2005). Comparison of muscle strength and flexibility between the preferred and non-preferred leg in English soccer players. Ergonomics, 48(11-14), 1568-1575. https://doi.org/10.1080/00140130500101585

Ringsberg, K., Gerdhem, P., Johansson, J., \& Obrant, K. J. (1999), Is there a relationship between balance, gait performance and muscular strength in 75-year-old women? Age and Ageing, 28, 289-293. https://doi.org/10.1093/ageing/28.3.289

Soslu, R., Güler, M., Özer, Ö., Devrilmez, M., Cincioğlu, G., Esen, H., \& Doğan, A. (2018). Boksörlerde Akut Yorgunluğun Statik Dengeye Etkisi. Journal of Sport, Education and Recreation. Retrieved from http://dergipark.gov.tr/sportive

Sterkowicz, S., \& Starosta, W. (2005). Selected factors influencing the level of general fitness in elite 
Greco-Roman wrestlers. J Hum Kinet, 14, 93.

Tatlici, A., Çakmakçi, E., Yilmaz, S., \& Arslan, F. (2018). Comparison of visual reaction values of elite deaf wrestlers and elite normally hearing wrestlers. Journal of Turkish Sport and Exercise, 20(2), 63-33. https://doi.org/10.15314/tsed.440813

Tatlici, A., \& Cakmakci, O. (2019). The effects of acute dietary nitrate supplementation on anaerobic power of elite boxers. Medicina Dello Sport, 72(2), 225-233.

Tatlici, A., Sercan Y., \& Samet A. (2018). Türkiye'de işitme engelliler ve spor. Türkiye birliği yayınları, 589-598.

Tatlici, A., \& Unlu, G. (2018). Elit Güreşçilerde Proprioseptif Nöromuskuler Fasilitasyon (Pnf) Uygulamalarının Dinamik Denge Performansına Akut Etkileri. Sportif Bakış: Spor ve Eğitim Bilimleri Dergisi, 57-63.

Wilkins, J. C., McLeod, T. C. V., Perrin, D. H., \& Gansneder, B. M. (2004). Performance on the balance error scoring system decreases after fatigue. Journal of Athletic Training, 39(2), 156.

\section{Copyrights}

Copyright for this article is retained by the author, with first publication rights granted to the journal.

This is an open-access article distributed under the terms and conditions of the Creative Commons Attribution license (http://creativecommons.org/licenses/by/4.0/). 